\title{
Reengineered Epipodophyllotoxin
}

\author{
Igor V. Magedov ${ }^{\mathrm{a}}$, Nikolai M. Evdokimov ${ }^{\mathrm{a}}$, Menuka Karki ${ }^{\mathrm{b}}$, Amanda S. Peretti ${ }^{\mathrm{c}}$, Dustin T. \\ Lima $^{a}$, Liliya Frolova ${ }^{a}$, Mary R. Reisenauer ${ }^{c}$, Anntherese E. Romero ${ }^{c}$, Paul Tongwa ${ }^{d}$, \\ Alexandr Fonarid, Jeff Altig ${ }^{a}$, Snezna Rogeljc, Mikhail Yu. Antipin ${ }^{d}$, Charles B. Shuster ${ }^{b}$, \\ and Alexander Kornienko ${ }^{a, e}$ \\ Igor V. Magedov: imagedov@nmt.edu; Alexander Kornienko: a_k76@txstate.edu \\ ${ }^{a}$ Department of Chemistry, New Mexico Institute of Mining and Technology, Socorro, New Mexico \\ 87801, USA \\ bDepartment of Biology, New Mexico State University, Las Cruces, New Mexico 88003, USA \\ 'Department of Biology, New Mexico Institute of Mining and Technology, Socorro, New Mexico \\ 87801, USA \\ dDepartment of Biology and Chemistry, New Mexico Highlands University, Las Vegas, New \\ Mexico 87701, USA \\ eDepartment of Chemistry and Biochemistry, Texas State University -San Marcos, San Marcos, \\ TX, 78666
}

\section{Abstract}

A variant structural skeleton of epipodophyllotoxin was synthesized and found to rival the natural cyclolignan in antiproliferative and microtubule destabilizing properties. This discovery leads to a new structural class of tubulin targeting agents.

Cyclolignan podophyllotoxin (1, Figure 1), isolated from American mayapple (Podophyllum peltatum), was extensively investigated as an antitumor agent, but the clinical results were disappointing due to severe gastrointestinal side effects. ${ }^{1}$ Its C-4 epimer epipodophyllotoxin (2), also found in the above-mentioned plant, ${ }^{2}$ is generally $5-10$ times less potent as an antiproliferative agent against cancer cells and as an inhibitor of in vitro mitotic spindle assembly. ${ }^{1,3-8}$ However, its glycosylated derivatives etoposide (3) and teniposide (4), commonly referred to as epipodopyllotoxins, are currently used in clinic for the treatment of lung and testicular cancers, lymphoma, non-lymphocytic leukemia and glioblastoma multiforme. ${ }^{3}$ Due to the development of drug resistance by cancer cells as well as side effects associated with the use of these agents in clinic, the search for new effective anticancer drugs with $\mathbf{1}$ and $\mathbf{2}$ as lead agents remains an intense area of research. ${ }^{4-6}$

Unfortunately, the complex chemical structure of podophyllotoxin prevents the generation of libraries of its analogues from simple commercially available materials. At the same time, the derivatization of podophyllotoxin as a means to obtain structure-activity relationship (SAR) information has the drawback of producing non-systematic data because it is limited by the type of chemistry that podophyllotoxin can undergo. For example, substitutions of rings $\mathrm{AB}$ and $\mathrm{E}$ by other moieties have been scarcely explored due to the synthetic challenge of removing the profuse oxygenation in these parts of the molecule (Figure 2). Limited

Correspondence to: Igor V. Magedov, imagedov@nmt.edu; Alexander Kornienko, a_k76@txstate.edu.

$\dagger$ Electronic Supplementary Information (ESI) available: Synthetic procedures, molecular biology methods, X-ray data, details of tubulin polymerization assay and computational work. See DOI: 10.1039/b000000x/ 
literature examples include ring E phenyl analogue 5 synthesized by Berkowitz and coworkers in 19 steps from commercially available materials ${ }^{9}$ and phenazine $\mathbf{6}$ prepared by way of oxidation of the $\mathrm{AB}$ subunit to an ortho-quinone and its subsequent condensation with 1,2-phenylenediamine. ${ }^{10}$ These reports constitute rare synthetic accomplishments illustrating the challenge of a systematic exploration of the chemical space occupied by these oxygenated moieties. ${ }^{11}$

Computer modeling simulations utilizing the tubulin-podophyllotoxin crystal structure ${ }^{12}$ revealed that the podophyllotoxin's pentacyclic framework can be mimicked with a dihydropyridine-based scaffold having comparable binding modes at the colchicine site. ${ }^{13}$ Because this mimetic dihydropyridine skeleton is easily accessible by a multicomponent reaction (MCR) of commercially available aromatic/heteroaromatic amines with aldehydes and tetronic acid, we prepared a diverse library of podophyllotoxin mimetics and generated systematic anticancer SAR data. ${ }^{13}$ In this method, the utilization of selected amine and aldehyde starting materials leads directly to the desired modifications of rings $\mathrm{AB}$ and $\mathrm{E}$, respectively (Figure 3 ). We found that compounds incorporating pyrazole $(\mathbf{8})$, indole $(\mathbf{9})$ and naphthalene (10) AB ring substitutions possessed nanomolar antiproliferative potencies. In addition, the trimethoxy substitution of ring $E$ was not critical as 3-bromopyridine and 3,5dibromophenyl rings were superior in many cases (e.g., 8 and 10). Although our MCR-based mimetic scaffold approach led to promising novel antitubulin agents (i.e., 8, 9 and 10) in its own right, we were intrigued by the possibility of utilizing this method as a tool to rapidly probe drastic skeleton modifications in the natural cyclolignans. With this idea in mind, we conceived reengineered epipodophyllotoxin 11, whose new naphthalene and 3,5dibromophenyl rings $\mathrm{AB}$ and $\mathrm{E}$ were inspired by the MCR product 10. In this communication, we report synthesis and anticancer evaluation of this unorthodox epipodophyllotoxin analogue.

The synthesis relied on an exo-selective intramolecular Diels-Alder reaction of ester 17, prepared using standard chemistry (Scheme 1). A simple reflux of $\mathbf{1 7}$ in toluene gave a 1.6:1 mixture of exo and endo products $\mathbf{1 8}$ and $\mathbf{1 9}$. These were easily separable and their structures were confirmed by single-crystal x-ray analyses. The desired C-4 hydroxyl was installed by the dihydroxylation of $\mathbf{1 8}$, which proceeded exclusively from the $\beta$-face furnishing diol $\mathbf{2 0}$ as a single diastereomer (Scheme 2). The synthesis of epipodophyllotoxin analogue 11 was then completed by a TFAA-promoted dehydration to give dihydronaphthalene $\mathbf{2 1}$ and its subsequent oxidation with DDQ. The structure of $\mathbf{1 1}$ was unambiguously established with x-ray crystallography. The synthetic work was completed by the preparation of additional analogues in the cis-lactone series. To this end, endo DielsAlder product 19 was subjected to the same three-reaction sequence leading to cis-lactone 24.

Evaluation of the synthesized analogues for antiproliferative activity was performed using HeLa and MCF-7 cancer cell lines as models for human cervical and breast adenocarcinomas, respectively (Table). In addition, we assessed the ability of these compounds to induce apoptosis in Jurkat cells (model for human T-cell leukemia) and calculated their binding energies using docking simulations (Table). The results indicated that in accordance with the literature data $\mathbf{2}$ was about an order of magnitude less potent in its antiproliferative effects than $\mathbf{1}$. Analogue 11, together with its dihydronaphthalene variant 21, exhibited submicromolar antiproliferative activity and potent apoptosis-inducing properties rivaling those of $\mathbf{2}$, in spite of their racemic nature. In addition, these four compounds displayed good binding affinities as revealed by Autodock simulations. This can also be seen in Figure 4 visually demonstrating that the matching enantiomer of reengineered epipodophyllotoxin $\mathbf{1 1}$ and its dihydronaphthalene analogue $\mathbf{2 1}$ bound to the colchicine site in orientations similar to that of $\mathbf{1}$. It should be noted that cis-lactone 
derivatives are significantly less active as revealed by literature reports ${ }^{4-6}$ as well as the results of the present investigation demonstrating decreased activity associated with cislactone analogues 22-24 and the absence of comparable binding modes in docking simulations.

Our mechanistic experiments confirm that compounds $\mathbf{2 1}$ and $\mathbf{1 1}$ retain the antitubulin mode of action of epipodophyllotoxin. Thus, $\mathbf{1 1}$ was found to arrest cancer cells in the G2/M phase of the cell cycle, exhibit little toxicity toward normal primary blood lymphocytes and (together with 21) display microtubule-destabilizing activity in vitro using a fluorimetrybased tubulin polymerization assay ${ }^{13}$ (see ESI for details). In addition, to determine the extent of microtubule disruption in whole cells, HeLa cells were cultured in the presence of carrier control (DMSO) or compounds $\mathbf{2 , 1 0 , 1 1}$ and 21 at the half maximal growth inhibitory concentration and examine for microtubule morphology (Figure 5). In contrast to DMSO-treated cells that displayed normal interphase and mitotic microtubule organization (A and F), compounds 2, 10, 11 and 21 all affected spindle morphology (G-J). Reengineered epipodophyllotoxin $\mathbf{1 1}$ exhibited the most potent destabilizing activity, completely blocking spindle formation $(\mathrm{G})$ and disrupting all but the most stable microtubules in interphase cells (B). Compounds 10, 2 and 21 had no effect on the relatively stable interphase microtubules (C-E), but did result in shorter spindle lengths, as evidenced by a $13,7.5$ and $15.2 \%$ decreases in pole-to-pole distances, respectively $(\mathrm{H}-\mathrm{J})$.

In conclusion, using our MCR-based mimetic scaffold approach we conceived and synthesized an epipodophyllotoxin analogue possessing a variant structural skeleton. Despite being racemic, this compound rivals the natural cyclolignan in its antiproliferative and apoptosis-inducing properties and induces dramatic microtubule disorganization effects in whole cells. Thus, compound $\mathbf{1 1}$ represents a new structural class of tubulin targeting agents. We are currently applying this interesting concept to other (e.g., compounds $\mathbf{8}$ and $\mathbf{9}$ ) podophyllotoxin-related frameworks as well as extending it to additional natural productbased drug discovery areas.

\section{Supplementary Material}

Refer to Web version on PubMed Central for supplementary material.

\section{Notes and references}

1. Imbert TF. Biochimie. 1998; 80:207-222. [PubMed: 9615861]

2. Bastos JK, Burnadt CL, Nanayakkara NPD, Bryant L, McChesney JD. J Nat Prod. 1996; 59:406408.

3. Bohlin L, Rosen B. Drug Discov Today. 1996; 1:343-351.

4. You YJ. Curr Pharm Des. 2005; 11:1695-1717. [PubMed: 15892669]

5. Gordaliza M, Castro MA, Corral JMM, San Feliciano A. Curr Pharm Des. 2000; 6:1811-1839. [PubMed: 11102564]

6. Lv M, Xu H. Mini-Rev Med Chem. 2011; 11:901-909. [PubMed: 21781026]

7. Gordaliza M, Castro MA, Garcia-Gravalos MD, Ruiz P, del Corral JMM, San Feliciano A. Arch Pharm. 1994:175-179.

8. Brewer CF, Loike JD, Horwitz SB, Sternlicht H, Gensler WJ. J Med Chem. 1979; 22:215-221. [PubMed: 423203]

9. Berkowitz DB, Maeng J-H, Dantzig AH, Shepard RL, Norman BH. J Am Chem Soc. 1996; 118:9426-9427.

10. Cho SJ, Kashiwada Y, Bastow KF, Cheng YC, Lee K-H. J Med Chem. 1996; 39:1396-1402. [PubMed: 8691469] 
11. For related pyridazine and indole A,B-ring analogues, see Bertounesque E, Imbert T, Monneret C. Tetrahedron. 1996; 52:14235-14246.Cline SD, Macdonald TL, Osheroff N. Biochemistry. 1997; 36:13095-13101. [PubMed: 9335572]

12. Ravelli RBJ, Gigant B, Curmi PA, Jourdain I, Lachkar S, Sobel A, Knossow M. Nature. 2004; 428:198-202. [PubMed: 15014504]

13. Magedov IV, Frolova L, Manpadi M, Bhoga UD, Tang H, Evdokimov NM, George O, Georgiou KH, Renner S, Getlic M, Kinnibrugh TL, Fernandes MA, van Slambrouck S, Steelant WFA, Shuster CB, Rogelj S, van Otterlo VLA, Kornienko A. J Med Chem. 2011; 54:4234-4246. and references cited therein. [PubMed: 21615090] 


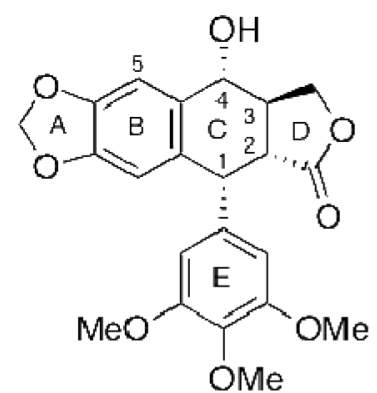<smiles>COc1cc([C@H]2c3cc4c(cc3[C@@H](O)[C@@H]3COC(=O)[C@H]23)OCO4)cc(OC)c1OC</smiles>

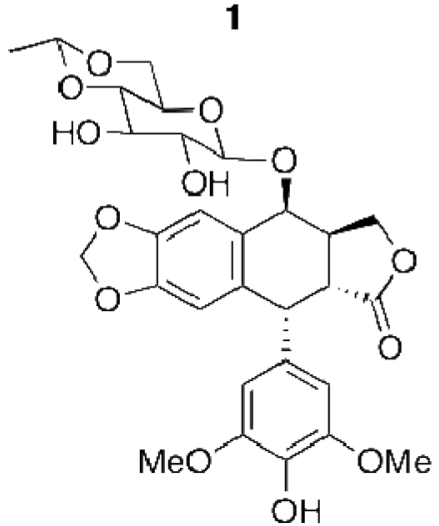

3

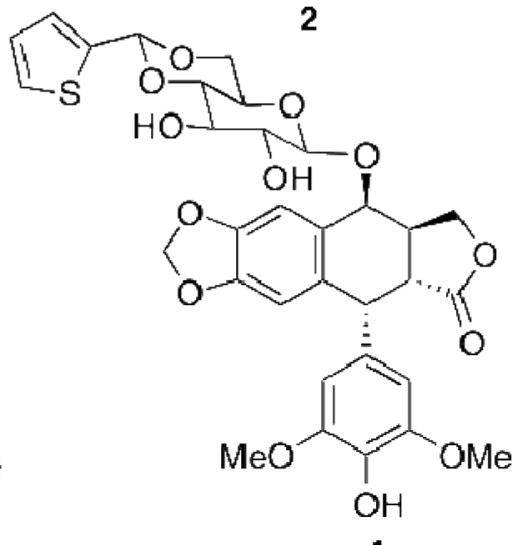

4

Figure 1.

Structures of podophyllotoxin (1), epipodophyllotoxin (2), etoposide (3) and teniposide (4). 
<smiles>COc1cc([C@H]2c3cc4c(cc3[C@@H](O)[C@@H]3COC(=O)[C@H]23)OCO4)cc(OC)c1OC</smiles>

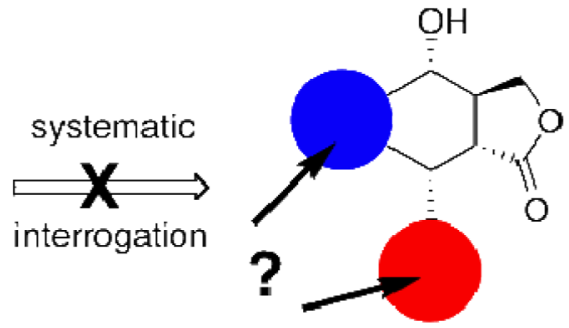<smiles>O=C1OC[C@H]2[C@@H](O)c3cc4c(cc3[C@@H](c3ccccc3)[C@@H]12)OCO4</smiles><smiles>COc1cc([C@H]2c3cc4nc5ccccc5nc4cc3[C@@H](O)C3COC(=O)[C@@H]32)cc(OC)c1OC</smiles>

Figure 2.

Is systematic interrogation of the chemical space occupied by rings $\mathrm{AB}$ and $\mathrm{E}$ possible? 

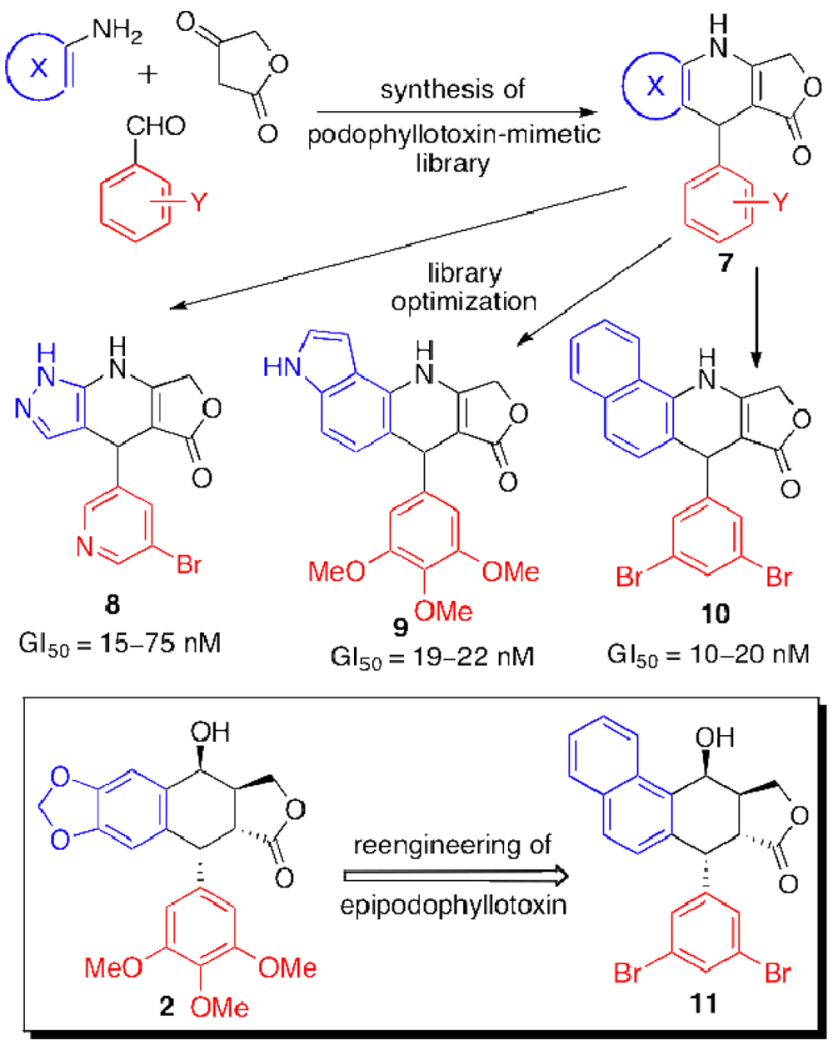

Figure 3.

Strategy leading to reengineered epipodophyllotoxin 11. 


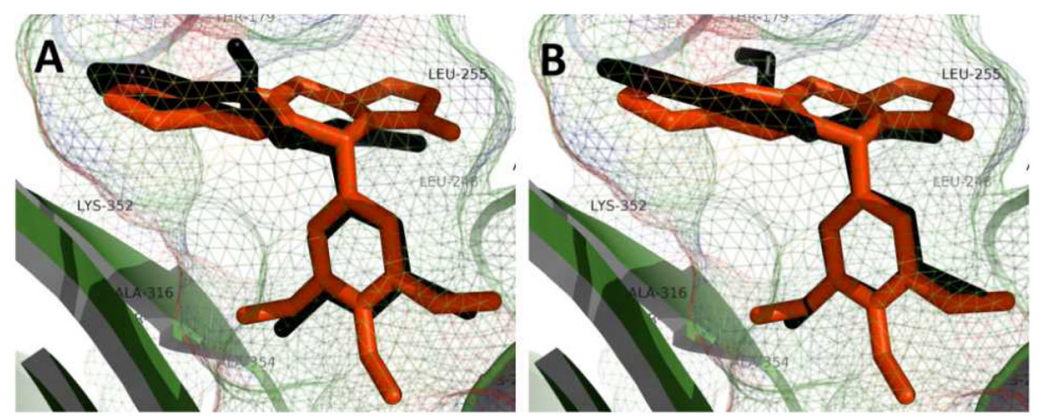

Figure 4.

Molecular docking poses (black) of $\mathbf{2 1}$ (A) and $\mathbf{1 1}$ (B) overlaid with that of $\mathbf{1}$ (red). 


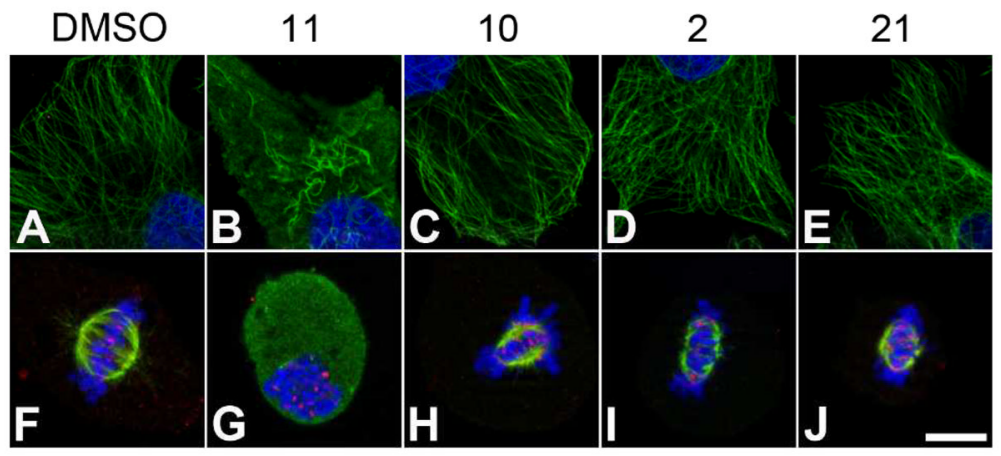

Figure 5.

Microtubule organization in HeLa cells during interphase $(\mathrm{A}-\mathrm{E})$ and mitosis $(\mathrm{F}-\mathrm{J})$. Hela cells were treated for 3 hours with the indicated compounds at their MTT-related $\mathrm{GI}_{50}$ concentrations (see Table). Following drug treatment, cells were probed for microtubules (green), centromeres (red) and DNA (blue). Bar, $10 \mu$. 


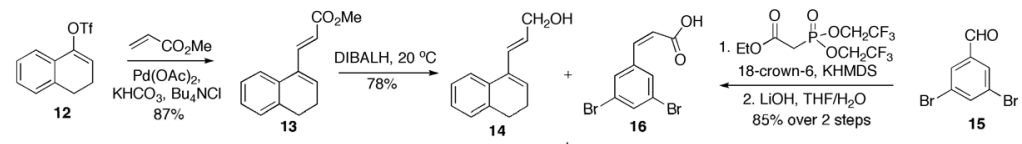

$\mathrm{DCC}$
$\mathrm{DMAP}$

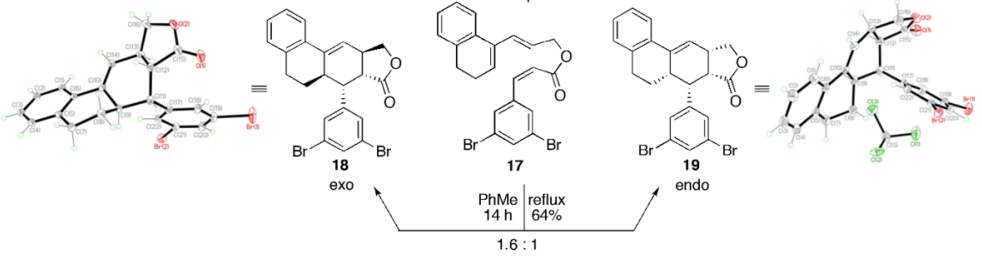

Scheme 1.

Synthesis of Diels-Alder products 18 (exo) and 19 (endo) 


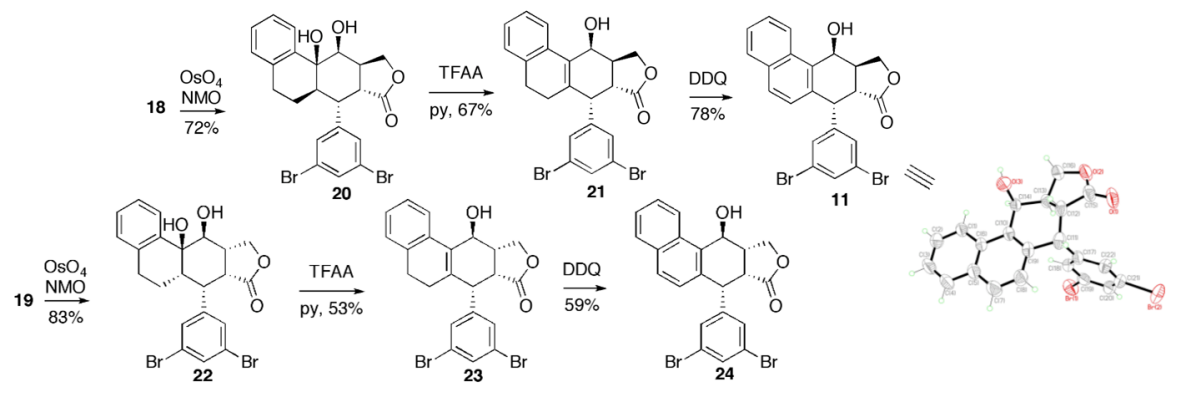

Scheme 2.

Elaboration of the Diels-Alder products $\mathbf{1 8}$ and $\mathbf{1 9}$ to reengineered epipodophyllotoxin $\mathbf{1 1}$ and its C-3 epimer 24. 


\section{Table}

Antiproliferative and apopotosis-inducing properties of the synthesized compounds, and their binding energies at the colchicine site.

\begin{tabular}{ccccc}
\hline$\#$ & GI $_{\mathbf{5 0}}(\boldsymbol{\mu M})^{\boldsymbol{a}}$ & apoptosis $^{\boldsymbol{b}}(\boldsymbol{\%})$ & binding energies $^{\boldsymbol{c}}(\mathbf{k J} / \mathbf{m o l})$ \\
\cline { 2 - 4 } & $\mathbf{H e L a}$ & MCF-7 & Jurkat & \\
\hline $\mathbf{1}$ & $0.030 \pm 0.002$ & $0.018 \pm 0.002$ & $37.5 \pm 1.9$ & -9.3 \\
$\mathbf{2}$ & $0.36 \pm 0.09$ & $0.24 \pm 0.00$ & $30.0 \pm 1.2$ & -9.2 \\
$\mathbf{1 0}$ & $0.016 \pm 0.002$ & $0.014 \pm 0.001$ & $27.7 \pm 3.2$ & -8.1 \\
$\mathbf{1 8}$ & $30.8 \pm 7.9$ & $23.7 \pm 0.8$ & $8.0 \pm 1.3$ & nd \\
$\mathbf{1 9}$ & $3.4 \pm 0.1$ & $4.4 \pm 0.2$ & $7.0 \pm 1.0$ & -7.0 \\
$\mathbf{2 0}$ & $42.2 \pm 1.0$ & $46.9 \pm 0.7$ & $7.5 \pm 0.4$ & $\mathrm{nd}$ \\
$\mathbf{2 1}$ & $0.22 \pm 0.00$ & $0.23 \pm 0.01$ & $28.5 \pm 1.3$ & -8.6 \\
$\mathbf{1 1}$ & $0.56 \pm 0.01$ & $0.43 \pm 0.05$ & $39.7 \pm 0.8$ & -8.4 \\
$\mathbf{2 2}$ & $56.9 \pm 3.4$ & $79.7 \pm 0.1$ & $7.3 \pm 0.6$ & $\mathrm{nd}$ \\
$\mathbf{2 3}$ & $41.4 \pm 3.0$ & $24.1 \pm 1.4$ & $7.7 \pm 1.4$ & $\mathrm{nd}$ \\
$\mathbf{2 4}$ & $12.9 \pm 2.4$ & $5.9 \pm 0.1$ & $7.4 \pm 0.7$ & $\mathrm{nd}$ \\
\hline
\end{tabular}

${ }^{a}$ Concentration required to reduce the viability of cells by $50 \%$ after $48 \mathrm{~h}$ of treatment with indicated compounds, relative to DMSO control \pm SD, determined by MTT assay.

$b_{\%}$ Apoptotic cells after $24 \mathrm{~h}$ of treatment with indicated compounds at the concentration of $300 \mathrm{nM}$ relative to DMSO control $\pm \mathrm{SD}$, determined by flow cytometric Annexin-V/propidium iodide assay.

${ }^{c}$ Binding energies revealed by Autodock Vina simulations, $\mathrm{nd}=$ no comparable binding pose. 